\title{
Effects of nutritional intervention by feeding high- protein foods containing BCAA for improving locomotive syndrome: Randomized Controlled Trial
}

YOSHIHIRO NAKAMURA ( $\square$ yoshihiro_nakamura@med.miyazaki-u.ac.jp )

University of Miyazaki

\section{TARO FUNAMOTO}

University of Miyazaki

TAKUYA TAJIMA

University of Miyazaki

HIROYUKI KIMURA

Otsuka Pharmaceutical Co. Ltd., Nutraceuticals Division Saga Nutraceuticals Research Institute KOICHIRO HAMADA

Otsuka Pharmaceutical Co. Ltd., Nutraceuticals Division Saga Nutraceuticals Research Institute ETSUO CHOSA

University of Miyazaki

\section{Research Article}

Keywords: locomotive syndrome, locomotion training, Locomo-call, high-protein food containing BCAA

Posted Date: January 5th, 2022

DOI: https://doi.org/10.21203/rs.3.rs-1228806/v1

License: () (1) This work is licensed under a Creative Commons Attribution 4.0 International License.

Read Full License 


\section{Abstract}

[Purpose] Exercise guidance is an effective measure against locomotive syndrome. Appropriate nutritional management is also considered necessary in order to maintain the motor function. This study is the first exploratory and prospective research on the effects of exercise guidance and feeding highprotein foods in order to improve locomotive syndrome, in elderly people.

[Method] We conducted a survey regarding five items related to locomotorium on the basic checklist prepared by the Japanese Ministry of Health, among men and women in their 60s and over living in Miyazaki Prefecture. Participation was solicited from those who responded "applicable" to three or more items, with those who gave their consent assigned to a food + exercise intervention group (EF group), an exercise intervention group (EX group), and a control group (C group) for research. Motor function surveys such as interviews, questionnaire, and locomotive syndrome risk test were conducted at the start of the study and three months later. The EX and EF groups were instructed to carry out locomotion training, while the EF group was asked to ingest one bag of high-protein test food daily immediately following exercise. The participants carried an activity meter and kept a record of their life in a diary during the study period. The EX and EF groups were encouraged to make recordings in a diary and carry an activity meter, while also getting a regular telephone contact once a week.

[Results] An improvement in the motor function was observed in the EX and EF group compared to the C group via Locomotive syndrome risk testing. While the muscle mass decreased significantly during the study period in the $C$ and EX group, no significant change was observed in limbs/trunk muscle mass in the EF group.

[Conclusion] The locomotion training improved the results of the Locomotive syndrome risk testing. Although muscle mass decreased with exercise guidance alone, muscle mass loss was suppressed by feeding high-protein foods in addition to exercise. We conclude that feeding high-protein foods is useful for improving motor function and maintaining muscle mass, in addition to exercise guidance, as a measure against locomotive syndrome in elderly.

\section{Background And Purpose}

Effective solutions are needed not only in the medical/nursing field but also in regard to society and the economy in Japan, which has reached the world's highest aging rate due to the aging of the population at an unprecedented rate in the world, backed up further by the population decline. One of the basic directions of "the Second terms of National Health Promotion Movement in the 21st Century (Health Japan 21 (the second term)" from 2013 to 2022, was to extend healthy life expectancy and reduce health inequalities, indicating its importance and urgency ${ }^{1)}$. "Locomotive Syndrome (commonly known as LS)," which was a concept newly proposed by the Japanese Orthopaedic Association (JOA) in 2007, refers to a condition with reduced mobility (walking, standing, sitting, etc.) due to disorders of the locomotive organs (bones, muscles, joints, etc.), wherein the risk of requiring nursing care increases as it progresses ${ }^{2,3)}$. The 
measures against "Locomo" are also included in Health Japan 21 (the second term) mentioned earlier, with goals set forth such as increasing the proportion of those who recognize Locomotive syndrome for the purpose of the health of the elderly and reducing the proportion of pain in the legs and back among elderly individuals. The background to this is the increase in the number of people and users covered by the long-term care insurance system.

Under the Japanese long-term care insurance system, you can receive long-term care services if you are bedridden or suffer from dementia and are in a state that requires constant care (state requiring long-term care), or if you need support in your daily life, such as with doing housework or getting dressed (state requiring support). According to a survey by the Ministry of Health, Labor and Welfare, the number of people certified as requiring support/nursing care has increased 2.9-fold, with the number of service users having increased 3.3-fold, during the past 17 years up to 2017, since the establishment of the long-term care insurance system ${ }^{4}$ ). While the factors requiring support/nursing care include "dementia," "cerebrovascular disease (stroke)," "weakness due to old age," etc., locomotor disorders such as "fractures/falling" and "joint disease" accounted for $24.8 \%$, or approximately $1 / 4$ of the total (according to the Ministry of Health, Labor and Welfare's Comprehensive Survey of Living Conditions) ${ }^{5)}$.

The Japanese Orthopaedic Association formulated "Locomotive syndrome risk test " in 2013 as a guideline for confirming mobility function. "Locomotive syndrome risk test" consists of three tests: (1) "Stand-up test (SUT)" to determine lower limb muscle strength; (2) "Two-Step test(TST)" to examine stride length; and (3) "the 25-question geriatric locomotive syndrome function scale (GLFS-25)" to evaluate physical condition and living conditions.

As a result of research to date, it has been found that instructing elderly individuals with impaired locomotion function to carry out locomotion training and confirming the implementation thereof by telephone three times a week, so-called Locomo-calls, for three months, have improved locomotive-related indicators, including Locomotive syndrome risk test ${ }^{6}$ ). Implementing Locomo-calls has made it possible to reduce variations in exercise implementation methods and food intake.

That said, previous studies have indicated that taking appropriate amounts of protein and carbohydrates immediately following exercise effectively increases muscle mass ${ }^{7)}$. While it is important to continue Locomotion-training for long periods of time, fatigue reduction and conditioning are also considered to be important factors for continuation. It is expected that the amount of exercise will increase further, as long as exercise can be continued with the intake of food having appropriate nutritional balance, which will lead to further improvement of conditions including locomotive syndrome related indicators.

The "BODYMAINTÉ Jelly" used this time is a health-nutrition product developed and sold by Otsuka Pharmaceutical Co., Ltd. The product contains $10 \mathrm{~g}$ of protein containing free branched-chain amino acids (BCAA) and Otsuka Pharmaceutical's original lactic acid bacterium B240. Because $10 \mathrm{~g}$ of protein can be supplemented by ingesting this product, it is suitable for ingestion immediately following exercise. Furthermore, it is a food product that is expected to have the effect of improving the intestinal 
environment via the action of lactic acid bacteria, enhancing immunity and managing the physical condition.

The purpose of this study was to investigate, for the first time, the effects of the combined use of exercise and daily life guidance along with the intake of BCAA-containing high-protein test food "BODYMAINTÉ Jelly" on the improvement of locomo-related indicators in elderly individuals with an impaired motor function.

\section{Subjects And Method}

This prospective study was carried out with the approval of the our Institutional Review Board (Research Project Number: 1-0027).

\subsection{Subjects}

The subjects included men and women aged 60 and over living in Miyazaki Prefecture, who were volunteers that responded "applicable" to three or more of the five items related to motor function on the "Basic Checklist" 8) prepared by the Ministry of Health, Labor and Welfare. All participants were given sufficient written explanations in order to obtain their written informed consent.

\subsection{Test food}

Table 1 shows the nutritional facts. The high-protein test food containing BCAA contains $2.5 \mathrm{~g}$ each of $B C A A^{9,10)}$ and arginine, which are ingredients that protect the muscles and promote recovery from muscle fatigue, in addition to whey protein that is quickly absorbed, wherein the amount of protein per product is equivalent to $10 \mathrm{~g}$. It is also fortified with $13 \mathrm{~g}$ of carbohydrates and vitamin $\mathrm{D}$. This product also contains lactic acid bacterium B240, which is a plant-derived lactic acid bacterium found in the fermented tea "Miyan" that is traditionally consumed in northern Thailand. "Miyan" is popular as a "food tea" or "chewed tea," in which fermented tea leaves itself are ingested, and has supported the health of local people since ancient times ${ }^{11}$ ). Furthermore, it has been reported that the oral ingestion of this product containing lactic acid bacterium B240 promoted the secretion of slgA in the saliva of healthy elderly people ${ }^{12}$ ) and elderly individuals with low physical activity ${ }^{13)}$, in addition to suppressing the prevalence of colds ${ }^{14)}$. Ingestion of this product containing BCAA and lactic acid bacterium B240 is expected to be effective for muscle recovery and physical condition maintenance following exercise.

\subsection{Method}

In addition to the basic checklist, the participants were evaluated on their declaration of health status, seven warning signs of Locomotive syndrome, height, weight, body mass index (BMI), abdominal circumference, blood pressure, pulse, and Locomotive syndrome risk test (SUT, TST, GLFS-25). Muscle mass and body fat mass were measured using a body composition analyzer (InBody S10, InBody Seoul, Korea). After adjusting for the number of people, gender, age, height, and weight, they were assigned to 
three groups: an exercise guidance group (EX group); an exercise guidance + high-protein food containing BCAA intake group (EF group); and a control group (C group), in order to implement a non-blinded intergroup comparative test (Fig. 1).

Every participant was asked to record a daily life diary. A triaxial accelerometer (Active style PRO HJA750C, OMRON Healthcare Co., Ltd. Kyoto) was worn to record the amount of activity. For the EX group, the basic exercises of "standing on one leg with eyes open" and "squat training" were performed, as locomotion training (loco-training), in addition to recording a life diary and wearing an activity meter. Furthermore, those participants who were able to exercise were asked to add "heel raises" and "front lunge" ${ }^{15}$ ). Locomotion training was instructed to be carried out three times a day and the implementation thereof was recorded in the life diary. For the EF group, in addition to the tasks assigned to the EX group, one bag of high-protein food containing BCAA (Table 1) was ingested once a day within 30 minutes after Loco-training. For group $\mathrm{C}$, the only tasks were to record a life diary and to wear an activity meter.

The test period was set as three months. During the test period, the EX group and the EF group were given Locomo-calls once a week in order to encourage them to continue locomotion training and ingest the test foods, by telephone or visiting, and at the same time, it was confirmed whether or not they had been recording in their life diary and carrying their activity meter. For Group C, phone calls or visits were made to check whether or not they had been recording in their life diary and carrying their activity meter, in addition to checking their physical condition. The data was collected once a month. After the expiration of the test period three months later, the same items as at the start of the test were evaluated and comparisons were made within the group and between groups.

\section{Exclusion criteria}

Exclusion criteria included those who did not consent to participate in this study, those who withdrew their consent during the study period, those who required assistance while walking, those who did not have sufficient records in their life diary and activity meter records, those who had an extremely high amount of activity due to participating in health classes, etc., on a daily basis, and those who had insufficient intake of test foods in the EF group.

\section{Statistical analysis}

Paired t-tests were used for comparisons within the same group, for the statistical analysis. One-way ANOVA (Tukey test) was used for comparison among the three groups. SAS release 9.4 (SAS Institute Inc, Cary, NC) was used for analysis, with the significance level set to $5 \%$.

\section{Results}

\subsection{Participants}


The study started in April 2018 and by August 2019, when the final registration was completed, the consent of 245 people had been obtained. Thirty of those (12.2\%) were suspended or had withdrawn, while 215 completed the three-month study period. Of these, we excluded 3 people with almost no data such as in their life diary and activity meter, 1 person with an extremely low intake rate of test foods, 1 person who participated in a health class on a daily basis, and 1 person with extremely high amount of activity during the test period, giving a number of subjects for efficacy analysis of 209 (85.3\%). There were $73(M=13, F=60)$ in the C group, $69(M=10, F=59)$ in the EX group, and $67(M=13, F=4)$ in the EF group. There was no significant difference between the groups in each group age and basic checklist (five motor function items) (Table 2).

\subsection{Locomotive syndrome risk tests (SUT, TST, GLFS-25)}

After completion of the 3-month test period, changes in motor function were examined by the Locomotive syndrome risk test. Even for the elderly individuals who had decreased motor function, which is applicable to the three items on the basic check list, significant improvement was observed in the SUT (one leg) in the EX group and EF group, who continuously performed Locomotion training (Table 3). The EF group exhibited significant improvement over the C group, in both the SUT (one leg) and (both legs), in the comparison between the groups. In the TST, the EX group significantly improved after 3 months of Locomotion training (Table 4). A comparison among the groups indicated significant improvement in both the EX group and the EF group, compared to the C group. GLFS-25 indicated significant improvement in both the EX group and the EF group after 3 months of Locomotion training (Table 5). A comparison among the groups indicated significant improvement in both the EX group and the EF group, compared to the $\mathrm{C}$ group.

\subsection{Body composition (weight and muscle mass)}

Changes in body composition due to the 3-month study intervention were evaluated using a body composition analyzer (Table 6). Body weight exhibited a significant decrease only in the $\mathrm{C}$ group. The EX/EF group exhibited a significantly higher value than the $C$ group, in terms of body weight change. Although a significant decrease was observed, with respect to the muscle mass, in the C group and EX group after 3 months of intervention, no significant difference was observed in the EF group. An intragroup comparison of muscle mass by site indicated a significant decrease in both the limbs and trunk after 3 months in the C Group, with a significant decrease in the lower limbs in the EX group. On the other hand, no significant changes were observed in either the limbs or trunk in the EF group. The 3-month change value of the intergroup comparison indicated a significant difference in the upper left limb and trunk, in the comparison between the $\mathrm{C}$ group and the $\mathrm{EF}$ group, and in the right lower limb in the comparison between the EX group and the EF group (Table 7).

\section{Discussion}


There have been some reports that the implementation of Locomotion training was useful for the subjects, mainly healthy elderly individuals ${ }^{16,17)}$. However, there is no report comparing the effects of Locomotion training and nutrition in elderly individuals with apparently impaired motor function. Therefore, in this study, we conducted an intervention study targeting people with impaired motor function, who responded "applicable" to three or more of the five items of locomotorium on the "basic checklist." With a short intervention of 3 months, significant improvement was observed in the Locomotive syndrome risk test in the Locomotion training intervention group (EF group/EX group) (Table 3-5). Locomotion training, the exercise used for intervention this time, is composed mainly of two types of exercises, "standing on one leg with eyes open" and "squat training," which is a simple and quick form of training. Furthermore, it can be carried out indoors, with no need for special equipment. Although the subjects undergoing Locomotion training already had deteriorated motor function, presumably rendering them at risk of falling, Locomotion training is also a form of training that can be carried out by adjusting the load according to their own abilities upon taking safety measures. Judging from the above, it was considered that Locomotion training is a safe and easy method for improving physical function even for elderly individuals, because it is an exercise program that is easy to continue.

It is important not only to have an appropriate exercise program but also to continue it, in order to improve motor function. This time, we implemented "Locomo-Calls" once a week in order to encourage the continuation of Locomotion training and the intake of test foods for the EX group and EF group by calling or visiting, and at the same time, checked and confirmed their life diary and whether or not they were carrying the triaxial accelerometer. We also implemented telephone calls and visits for the $\mathrm{C}$ group once a week in order to check their life diary, whether or not they were carrying the triaxial accelerometer, and to confirm their physical condition. There were 245 people who consented to participate in this study. We assume that continuous contact to implement "Locomo-calls" and encourage recording in their diaries and carrying triaxial accelerometer led to a high number of subjects for effectiveness analysis of 209 (85.3\%), as a result. Because it has been reported that "Locomo-calls" motivated participation in the study ${ }^{18,19)}$, it was also indicated in this study that regular "Locomo-calls" were useful for continuing Locomotive training.

It is noteworthy that muscle mass decreased in the EX group, while improving motor function, as a result. Because locomotive syndrome emphasizes mobility, Locomotive training focuses on lower limb training. Nevertheless, in the evaluation of muscle mass by site using a body composition analyzer, the muscle mass of the lower limbs with exercise intervention had decreased more than that of the upper limbs without exercise intervention, in the EX group (Table 7). Loss of muscle mass is quite simply sarcopenia and it has been pointed out that sarcopenia is associated with locomotive syndrome ${ }^{20}$. Even if exercise intervention alone shows temporary improvement in motor function, it may not be possible to expect further improvement because the muscles do not increase, making it potentially difficult to maintain.

It is necessary to take measures to prevent muscle loss during weight loss associated with exercise therapy. It is said that the onset mechanism of sarcopenia is related to the intake of protein, which is essential for maintaining muscle mass among nutrients ${ }^{21)}$; moreover, there are also reports of low 
protein intake in humans with sarcopenia ${ }^{22}$. On the other hand, if the protein intake is high, the elderly are said to be able to obtain the same anabolic effect as the young ${ }^{23)}$. However, if a sufficient intake cannot be obtained, sufficient biosynthesis cannot be obtained. It has been reported that one of the factors for this is that the elderly are less sensitive to $B C A A^{24)}$. Therefore, active feeding of $B C A A$ in the elderly results in anabolic effects, consequently allowing sarcopenia to be prevented. In other words, rather than giving exercise guidance alone to the elderly, multidisciplinary nutrition management guidance that takes nutrients and other vitamins ${ }^{25}$ ) into consideration is important. On the other hand, it has been reported that the intake of supplements containing not only protein but also carbohydrates dramatically improved the ability of muscle protein biosynthesis, compared to the intake of protein alone ${ }^{26)}$. The high-protein test food tested this time contains $2500 \mathrm{mg}$ of BCAA and arginine that make up muscle, as well as $13 \mathrm{~g}$ of carbohydrates. This study indicated that although exercise alone resulted in muscle loss, the ingestion of high-protein foods containing BCAA immediately following exercise may help maintain muscle mass.

Regarding the limitations associated with this study, although it can be said that the number of subjects was small, it was difficult to gather elderly individuals who had no underlying disease and had decreased motor function, so conversely, it is believed that the study was possible because Japan is facing a superaging society. We assume that it will be a reference for countries that will enter a super-aging society in the future. Second, the follow-up period was 3 months. We were able to prove that it was effective despite the study being conducted for only a short period of time, and that sustaining the effect for a long period of time was related to the continuation method, so it is necessary to consider it from another perspective. The "Locomo-calls" we are advocating as a solution appear to be one method. Furthermore, the fact that it was not possible to obtain an increase in muscle mass, even in the EF group with food intervention, despite the improvement in motor function obtained in this intervention test of Locomotive training and test food, indicates a need for further study going forward.

\section{Conclusion}

While Locomotion training program using "Locomo-calls" was useful for improving the locomotive syndrome related indicators such as a countermeasure against locomotive syndrome in the elderly with a decreased motor function, exercise intervention alone resulted in a decrease in muscle mass. On the other hand, ingesting a BCAA-containing high-protein test food suppressed muscle mass loss. Not only exercise intervention but also a continuous nutrition intake was useful among elderly individuals with impaired motor function. Elderly individuals with locomotive syndrome exhibit a significant decrease in muscle mass due to aging, so it is indispensable to intake foods that can be easily consumed, allowing them to expect to maintain muscle mass, in addition to exercise therapy. Especially in the case of elderly individuals with an impaired motor function, the importance of nutrition and exercise guidance in regular life guidance was stressed once again.

\section{Declarations}


Conflict of interest

Research grants received from Otsuka Pharmaceutical Co., Ltd.

Provision of "BODYMAINTÉ Jelly", a high-protein food containing BCAA

Acknowledgments

We would like to thank the subjects, the staff members in the Tsuno Town Welfare Division, and the Kijo Town Welfare and Health Division, for their cooperation in conducting this research. Furthermore, we would like to express our deep gratitude to Ms. Michiko Sugita, Ms. Anna Koide, Ms. Megumi Iwakiri, Mr. Koki Ouchi and other staff members of the Department of Orthopedic Surgery, Faculty of Medicine, University of Miyazaki, who cooperated with data creation and management, and Mr. Hisashi Tanaka, Scientific Affairs Department, Nutraceuticals Division, Otsuka Pharmaceutical Co., Ltd.

\section{References}

1)Ministry of Health, Labour and Welfare. Health Japan 21 (the second term). https://www.mhlw.go.jp/file/06-Seisakujouhou-10900000-Kenkoukyoku/0000047330.pdf

2) Nakamura K. A “super-aged" society and the "locomotive syndrome”.J Orthop Sci 2008; 13:1-2.

3) Nakamura K. The concept and treatment of locomotive syndrome: itsacceptance and spread in Japan. J Orthop Sci 2011; 16: 489-491.

4) General Affairs Division, Health and Welfare Bureau for the Elderly, Ministry of Health, Labour and Welfare: FY 2018 Current status and future role of the national system of care insurance. https://www.mhlw.go.jp/file/06-Seisakujouhou-12300000-Roukenkyoku/0000213177.pdf. p3

5)Ministry of Health, Labour and Welfare(2019) Comprehensive Survey of Living Conditions 2019.https://www.mhlw.go.jp/toukei/saikin/hw/k-tyosa/k-tyosa19/index.html

6)Chosa E. [Locomotive syndrome and frailty. Locomotive syndrome due to the underlying disease of degenerative arthritis]. Clin Calcium 2012 Apr;22(4):49-57.

7)Hiroyasu Mori, Yasunobu Tokuda. Effect of whey protein supplementation after resistance exercise on the muscle mass and physical function of healthy older women: A randomized controlled trial. Geriatr Gerontol Int. 2018 Sep;18(9):1398-1404.

8) Ministry of Health, Labour and Welfare. Basic Health check lists. https://www.mhlw.go.jp/topics/2009/05/dl/tp0501-1f_0005.pdf

9) Michael V Fedewa, Steven O Spencer, Tyler D Williams, Zachery E Becker, Collin A Fuqua. Effect of branched-Chain Amino Acid Supplementation on Muscle Soreness following Exercise: A Meta-Analysis. 
Int J Vitam Nutr Res. 2019 Nov;89(5-6):348-356.

10) Dong-Hee Kim, Seok-Hwan Kim, Woo-Seok Jeong, Ha-Yan Lee. Effect of BCAA intake during endurance exercises on fatigue substances, muscle damage substances, and energy metabolism substances. J Exerc Nutrition Biochem. 2013 Dec;17(4):169-80.

11) OKADA Sanae. The World of Plant Origin Lactic Acid Bacteria. J Gen Appl Microbiol. 1986;32:57-65

12) Yoshifumi Kotani, Shoji Shinkai, Hiroshi Okamatsu, Masamichi Toba, Kishiko Ogawa, Hiroto Yoshida, Taro Fukaya, Yoshinori Fujiwara, Paulo Hm Chaves, Keiji Kakumoto, Noriyuki Kohda. Oral intake of Lactobacillus pentosus strain b240 accelerates salivary immunoglobulin A secretion in the elderly: A randomized, placebo-controlled, double-blind trial. Immun Ageing. 2010;7:11.

13) Kazuhiro Shimizu, Hironori Sato, Yoko Suga, Satoko Yamahira, Masamichi Toba, Koji Hamuro, Keiji Kakumoto, Noriyuki Kohda, Takao Akama, Ichiro Kono, Shinya Kuno. The effects of Lactobacillus pentosus strain b240 and appropriate physical training on salivary secretory IgA levels in elderly adults with low physical fitness: a randomized, double-blind, placebo-controlled trial. J Clin Biochem Nutr. 2014 Jan;54(1):61-6

14) Shinkai S, Toba M, Saito T, Sato I, Tsubouchi M, Taira K, Kakumoto $K$, Inamatsu T, Yoshida H, Fujiwara Y, Fukaya T, Matsumoto T, Tateda K, Yamaguchi K, Kohda N, Kohno S. Immunoprotective effects of oral intake of heat-killed Lactobacillus pentosus strain b240 in elderly adults: a randomised, doubleblind, placebo-controlled trial. Br J Nutr. 2013 May;109(10):1856-65.

15) The Japanese Orthopedic Association Corporation: Locomo Challenge Promotion Conference, LOCOMO Pamphlets FY 2015 version https://locomo-joa.jp/news/upload_images/locomo_pf2015.pdf. p11-12.

16)Kota Munetsugu, Marie Moriishi, Ayane Hazama, Keiko Hiramoto. Assessment of the effects of a group intervention program used in home-dwelling elderly individuals to promote home exercise and prevent locomotive syndrome. J. Phys. Ther. Sci. 2019; 31:470-474.

17)Toshinori Yoshihara, Hayao Ozaki, Takashi Nakagata, Toshiharu Natsume, Tomoharu Kitada, Yoshihiko Ishihara, Pengyu Deng, Takuya Osawa, Masayoshi Ishibashi, Muneaki Ishijima, Hiroyuki KobaYashi, Shuichi Machida, Hisashi Naito. Effects of a progressive walking program on the risk of developing locomotive syndrome in elderly Japanese people: a single-arm trial. J. Phys. Ther. Sci. 2018; 30:1180-1186.

18)Mari Hashimoto, Seiji Yasumura, Kyoko Nakano, Midori Kimura, Kozo Nakamura, Keiji Fujino, Hiromoto Ito. Feasibility study of locomotion training in an home-visit preventive care program. Nippon Ronen Igakkai Zasshi. 2012;49:476-482. 
19)Tomoyuki Arai, Hiroaki Fujita, Kohei Maruya, Yoshizawa Shinta, Ryoma Asahi, Yasuhiro Morita, Hideaki Ishibashi. The investigation of improvement effect on physical function and its sustainability after 6 months by "LOCOMO CALL" program as municipal nursing care prevention project. The Journal of Japan Osteoporosis Society. 2018;4(4):531-540.

20)Noriko Yoshimura, Shigeyuki Muraki, Toshiko lidaka, Hiroyuki Oka, Chiaki Horii, Hiroshi Kawaguchi, Toru Akune, Kozo Nakamura, Sakae Tanaka. Prevalence and co-existence of locomotive syndrome, sarcopenia, and frailty: the third survey of Research on Osteoarthritis/Osteoporosis Against Disability (ROAD) study. J Bone Miner Metab. 2019 Nov;37(6):1058-1066.

21)Cruz-Jentoft AJ, Baeyens JP, Bauer JM et al. European Working Group on Sarcopenia in Older People. Sarcopenia: European consensus on definition and diagnosis. Report of the European Working Group on Sarcopenia in Older People. Age Ageing 39:412-423, 2010

22) J P Chaput, C Lord, M Cloutier, M Aubertin Leheudre, E D B Goulet, S Rousseau, A Khalil, I J Dionne. Relationship between antioxidant intakes and class I sarcopenia in elderly men and women. J Nutr Health Aging. Jul-Aug 2007;11(4):363-9.

23) Volpi, E., M. Sheffield-Moore, B.B. Rasmussen, et al., Basal muscle amino acid kinetics and protein synthesis in healthy young and older men. JAMA, 2001. 286(10):1206-1212.

24) Katsanos CS, Kobayashi H, Sheffield-Moore M, Aarsland A, Wolfe RR. A high proportion of leucine is required for optimal stimulation of the rate of muscle protein synthesis by essential amino acids in the elderly. Am J Physiol Endocrinol Metab. 2006 Aug;291(2):E381-7.

25)Verreijen AM, et al. A high whey protein-, leucine-, and vitamin D-enriched supplement preserves muscle mass during intentional weight loss in obese older adults: a double-blind randomized controlled trial. Am J Clin Nutr. 2015;101 (2):279-86.

26)Rasmusen,B.B.,S.Fujita,R.R.Wolfe,etal. : Insulin resistance of muscle protein metabolism in aging. FASEB J.,2006.20(6):p.768-769.

\section{Tables}

Table 1 Nutritional facts for high-protein food containing lactic acid bacteria

(Product name: BODYMAINTÉ Jelly (Otsuka Pharmaceutical)

Nutrition facts label per bag $(100 \mathrm{~g})$ of product 
Energy: $90 \mathrm{kcal}$,

Protein: $10 \mathrm{~g}$, Fat: $0 \mathrm{~g}$, Carbohydrates: $13 \mathrm{~g}$

Sodium: $0.11 \mathrm{~g}$, Vitamin B6: $5 \mathrm{mg}$, Vitamin D:10 $\mu \mathrm{g}$

Amino acid: 2,500 mg (Valine: 500 mg, Leucine: 1,000 mg, Isoleucine: 500 mg, Arginine: 500 mg), Citric acid: $1,250 \mathrm{mg}$

Lactic acid bacteria: B240

Table 2. Participant background by group (at $\mathrm{OM}$ measurement)

\begin{tabular}{llll}
\hline & C group & EX group & EF group \\
\hline Number of participants $\mathrm{n}$ & 73 & 69 & 67 \\
\hline Average age \pm SD & $79.0 \pm 8.2$ & $78.6 \pm 6.7$ & $77.6 \pm 6.6$ \\
\hline Basic checklist (five items related to motor function) Score & $3.5 \pm 0.7$ & $3.5 \pm 0.7$ & $3.4 \pm 0.6$ \\
\hline Height $(\mathrm{cm})$ & $148.5 \pm 8.0$ & $150.6 \pm 7.3$ & $149.7 \pm 7.3$ \\
\hline Weight $(\mathrm{kg})$ & $52.6 \pm 10.0$ & $54.1 \pm 8.3$ & $52.4 \pm 9.8$ \\
\hline BMI (Body Mass Index) $(\mathrm{kg} / \mathrm{m} 2)$ & $23.7 \pm 3.3$ & $23.8 \pm 2.7$ & $23.3 \pm 3.6$ \\
\hline Have a medical history $\mathrm{n}(\%)$ & $67(74.6)$ & $60(91.8)$ & $50(87.0)$ \\
\hline Presence or absence of pain $\mathrm{n}(\%)$ & $55(75.3)$ & $50(72.5)$ & $42(62.7)$ \\
\hline Knee pain & $20(27.4)$ & $30(43.5)$ & $31(46.3)$ \\
\hline Lower back pain & $33(45.2)$ & $23(33.3)$ & $24(35.8)$ \\
\hline Hip pain & $9(12.3)$ & $4(5.8)$ & $1(16.4)$ \\
\hline Shoulder pain & $18(24.7)$ & $17(24.6)$ & $8(11.9)$ \\
\hline Other pain & $6(8.2)$ & $4(5.8)$ & $8(11.9)$
\end{tabular}

N.S. one-way ANOVA 
Table 3. Locomotive syndrome risk testing Stand-up test (both legs/one leg) (MEAN $\pm S D$ )

Stand-up test (both legs) $(\mathrm{cm})$

$\mathrm{OM}$

$3 \mathrm{M}$

Change

value
Stand-up test (one leg) $(\mathrm{cm})$

$0 \mathrm{M} \quad 3 \mathrm{M}$

$47.6 \pm 4.6 \quad 47.6 \pm 4.9 \quad 0.0 \pm 3.4$

$48.0 \pm 4.7 \quad 46.8 \pm 5.6 * a \quad-1.2 \pm 3.7$

EX

Group

EF

Group
$20.0 \pm 10.7 \quad 20.6 \pm 11.2 \quad 0.6 \pm 9.2$

$18.3 \pm 8.4$

$17.1 \pm 8.4$

$-1.2 \pm 5.0$

$-0.6 \pm 4.2$

${ }^{*} \mathrm{C}$
$46.0 \pm 5.5 \quad 44.8 \pm 5.9$

*ac
Change value

*a Significantly different $(p<0.05)$ from the values of $0 M$ by paired $t$ test

${ }^{*} \mathrm{C}$ Significantly different $(\mathrm{p}<0.05)$ from the values of group $C$ and $E F$ $(n: C=71, E X=69, E F=67)$

Table 4. Locomotive syndrome risk testing 2-step test (MEAN $\pm S D$ ) 2-step test

\begin{tabular}{llll}
\hline & OM & $3 \mathrm{M}$ & Change value \\
\hline C group & $1.107 \pm 0.258$ & $1.109 \pm 0.256$ & $0.002 \pm 0.144$ \\
\hline EX group & $1.190 \pm 0.186$ & $1.250 \pm 0.187 *_{\mathrm{ab}}$ & $0.060 \pm 0.111 * \mathrm{~b}$ \\
\hline EF group & $1.195 \pm 0.212$ & $1.208 \pm 0.205{ }^{*} \mathrm{C}$ & $0.013 \pm 0.112$
\end{tabular}

*a Significantly different $(\mathrm{p}<0.05)$ from the values of $0 \mathrm{M}$ by paired $t$ test

*b Significantly different $(p<0.05)$ from the values of group $C$ and $E X$

${ }^{*} \mathrm{C}$ Significantly different $(\mathrm{p}<0.05)$ from the values of group $C$ and $E F$

$(n: C=70, E X=69, E F=67)$ 
Table 5 Locomotive syndrome risk testing GLFS-25 (MEAN \pm SD)

\begin{tabular}{|c|c|c|c|}
\hline & \multicolumn{3}{|l|}{ Locomo 25} \\
\hline & $\mathrm{OM}$ & $3 \mathrm{M}$ & Change value \\
\hline C group & $16.5 \pm 13.8$ & $15.0 \pm 12.9$ & $-1.5 \pm 9.1$ \\
\hline EX group & $13.1 \pm 10.2$ & $9.9 \pm 9.6 * a b$ & $-3.2 \pm 6.3$ \\
\hline EF group & $12.0 \pm 14.2$ & $9.5 \pm 11.9 * a c$ & $-2.4 \pm 8.4$ \\
\hline \multicolumn{4}{|c|}{ *a Significantly different $(p<0.05)$ from the values of $0 \mathrm{M}$ by paired $t$ tes } \\
\hline \multicolumn{4}{|c|}{ *b Significantly different $(p<0.05)$ from the values of group $C$ and EX } \\
\hline \multicolumn{4}{|c|}{${ }^{{ }^{C} \mathrm{C} \text { Significantly different }(}(\mathrm{p}<0.05)$ from the values of group $C$ and $E F$} \\
\hline$(n: C=73, E$ & $, E F=67)$ & & \\
\hline
\end{tabular}

Table 6 Measured values of body composition (body weight, muscle mass, body fat mass, water content) and changes thereof (MEAN \pm SD)

\begin{tabular}{|c|c|c|c|c|c|c|}
\hline & \multicolumn{3}{|l|}{ Weight(kg) } & \multicolumn{3}{|c|}{ Muscle mass(kg) } \\
\hline & $0 \mathrm{M}$ & $3 \mathrm{M}$ & $\begin{array}{l}\text { Change } \\
\text { value }\end{array}$ & $0 \mathrm{M}$ & $3 \mathrm{M}$ & $\begin{array}{l}\text { Change } \\
\text { value }\end{array}$ \\
\hline C group & $52.6 \pm 10.0$ & $\begin{array}{l}52.1 \pm 10.4 \\
*_{a}\end{array}$ & $-0.5 \pm 1.7$ & $32.4 \pm 6.1$ & $\begin{array}{l}31.9 \pm 5.9 \\
* a\end{array}$ & $-0.5 \pm 1.3$ \\
\hline $\begin{array}{l}\text { EX } \\
\text { group }\end{array}$ & $54.1 \pm 8.3$ & $54.2 \pm 8.1$ & $0.1 \pm 1.5$ *b & $33.4 \pm 4.7$ & $\begin{array}{l}32.7 \pm 4.5 \\
* a\end{array}$ & $-0.7 \pm 1.2$ \\
\hline $\begin{array}{l}\text { EF } \\
\text { group }\end{array}$ & $52.4 \pm 9.8$ & $52.7 \pm 9.9$ & $0.3 \pm 1.2 * \mathrm{C}$ & $32.5 \pm 5.1$ & $32.2 \pm 5.1$ & $-0.2 \pm 1.4$ \\
\hline
\end{tabular}

*a Significantly different $(p<0.05)$ from the values of $0 M$ by paired $t$ test

*b Significantly different $(p<0.05)$ from the values of group $C$ and EX

${ }^{*}$ C Significantly different $(p<0.05)$ from the values of group $C$ and $E F$

Weight ( $\mathrm{n}: \mathrm{C}=73, \mathrm{EX}=69, \mathrm{EF}=67$ )

Muscle mass ( $\mathrm{n}: \mathrm{C}=66, \mathrm{EX}=67, \mathrm{EF}=60)$ 
Table 7 Measured value of muscle mass by site and change values thereof (MEAN $\pm S D$ )

\begin{tabular}{|c|c|c|c|c|c|c|}
\hline & \multicolumn{3}{|c|}{ Right upper limb (kg) } & \multicolumn{3}{|c|}{ Left upper limb (kg) } \\
\hline & OM & $3 \mathrm{M}$ & $\begin{array}{l}\text { Change } \\
\text { value }\end{array}$ & OM & $3 \mathrm{M}$ & $\begin{array}{l}\text { Change } \\
\text { value }\end{array}$ \\
\hline C group & $1.62 \pm 0.51$ & $\begin{array}{l}1.58 \pm 0.50 \\
* a\end{array}$ & $-0.04 \pm 0.10$ & $1.61 \pm 0.51$ & $\begin{array}{l}1.57 \pm 0.49 \\
* a\end{array}$ & $-0.04 \pm 0.10$ \\
\hline $\begin{array}{l}\text { EX } \\
\text { group }\end{array}$ & $1.63 \pm 0.34$ & $1.61 \pm 0.35$ & $-0.02 \pm 0.10$ & $1.62 \pm 0.33$ & $1.60 \pm 0.35$ & $-0.02 \pm 0.10$ \\
\hline \multirow[t]{3}{*}{$\begin{array}{l}\text { EF } \\
\text { group }\end{array}$} & $1.57 \pm 0.36$ & $1.57 \pm 0.39$ & $0.0 \pm 0.10$ & $1.54 \pm 0.36$ & $1.55 \pm 0.39$ & $\begin{array}{l}0.01 \pm 0.10 \\
{ }^{{ }^{*} \mathrm{C}}\end{array}$ \\
\hline & \multicolumn{3}{|c|}{ Right lower limb (kg) } & \multicolumn{3}{|c|}{ Left lower limb (kg) } \\
\hline & OM & $3 \mathrm{M}$ & $\begin{array}{l}\text { Change } \\
\text { value }\end{array}$ & OM & $3 \mathrm{M}$ & $\begin{array}{l}\text { Change } \\
\text { value }\end{array}$ \\
\hline C group & $4.99 \pm 1.31$ & $\begin{array}{l}4.88 \pm 1.24 \\
* a\end{array}$ & $-0.10 \pm 0.34$ & $4.98 \pm 1.25$ & $\begin{array}{l}4.89 \pm 1.21 \\
* a\end{array}$ & $-0.09 \pm 0.32$ \\
\hline $\begin{array}{l}\text { EX } \\
\text { group }\end{array}$ & $5.32 \pm 1.17$ & $\begin{array}{l}5.12 \pm 0.98 \\
*_{a}\end{array}$ & $-0.20 \pm 0.45$ & $5.28 \pm 1.14$ & $\begin{array}{l}5.10 \pm 0.98 \\
\text { *a }\end{array}$ & $-0.18 \pm 0.42$ \\
\hline \multirow[t]{3}{*}{$\begin{array}{l}\text { EF } \\
\text { group }\end{array}$} & $5.08 \pm 1.24$ & $5.06 \pm 1.19$ & $\begin{array}{l}-0.03 \pm 0.32 \\
* d\end{array}$ & $5.10 \pm 1.20$ & $5.06 \pm 1.18$ & $-0.04 \pm 0.32$ \\
\hline & \multicolumn{6}{|l|}{ Trunk (kg) } \\
\hline & $0 \mathrm{M}$ & $3 \mathrm{M}$ & $\begin{array}{l}\text { Change } \\
\text { value }\end{array}$ & & & \\
\hline C group & $15.19 \pm 3.31$ & $\begin{array}{l}14.99 \pm 3.26 \\
* a\end{array}$ & $-0.20 \pm 0.52$ & & & \\
\hline $\begin{array}{l}\text { EX } \\
\text { group }\end{array}$ & $15.33 \pm 2.27$ & $15.29 \pm 2.35$ & $-0.05 \pm 0.52$ & & & \\
\hline $\begin{array}{l}\text { EF } \\
\text { group }\end{array}$ & $15.01 \pm 2.48$ & $15.04 \pm 2.64$ & $\begin{array}{l}0.03 \pm 0.55 \\
{ }^{*} \mathrm{C}\end{array}$ & & & \\
\hline \multicolumn{7}{|c|}{ *a Significantly different $(p<0.05)$ from the values of $0 M$ by paired $t$ test } \\
\hline \multicolumn{7}{|c|}{${ }^{{ } \mathrm{C}}$ Significantly different $(p<0.05)$ from the values of group C and EF } \\
\hline \multicolumn{7}{|c|}{ *d Significantly different $(p<0.05)$ from the values of group EX and EF } \\
\hline
\end{tabular}

\section{Figures}




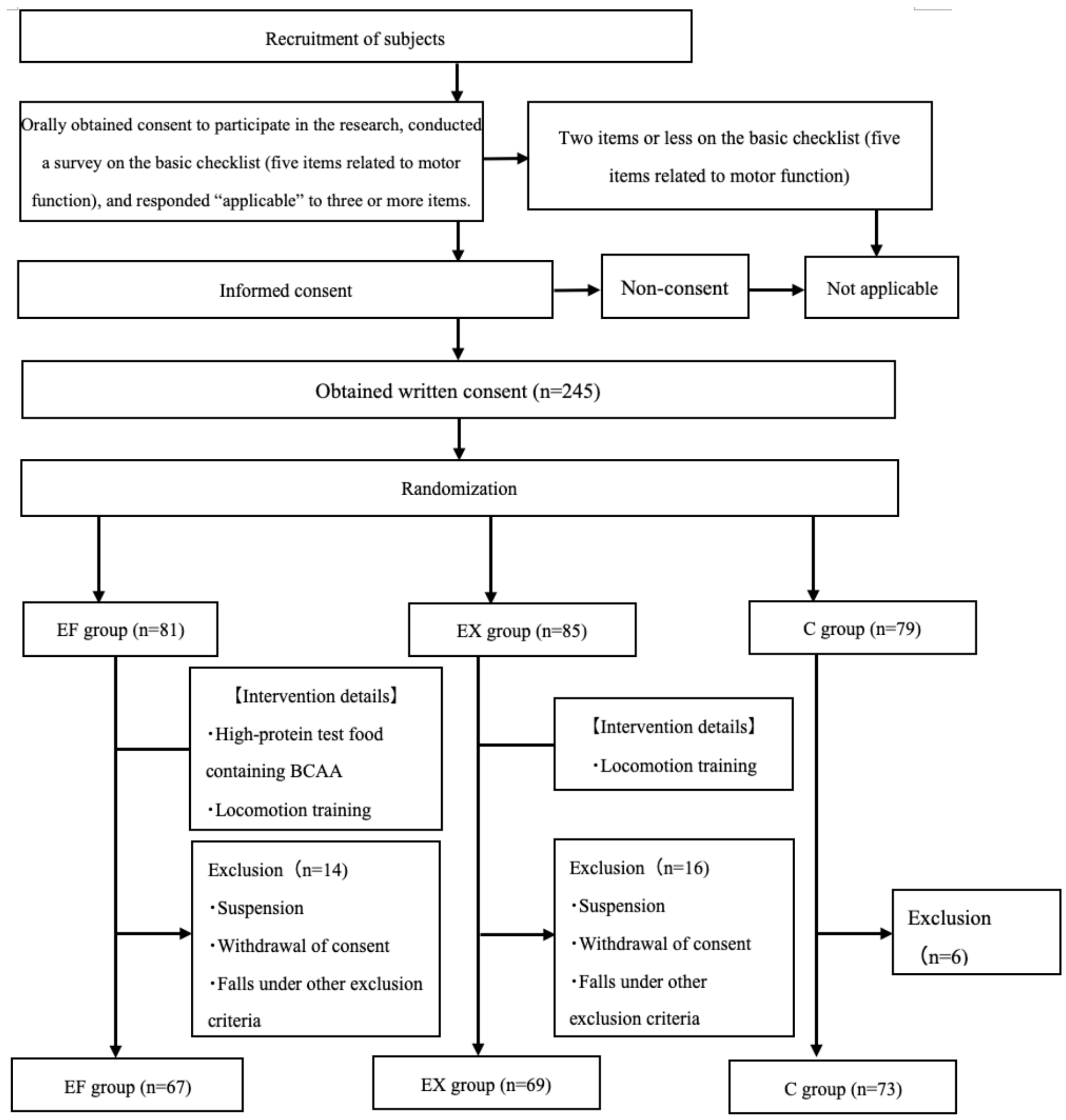

Figure 1

Test design flowchart 